\title{
A novel Halomonas species isolated from a deep-sea sediment sample of the New Britain Trench exhibits high anti-oxidative stress capability
}

\author{
ZHE XIE ${ }^{1}$, FANGFANG YAN ${ }^{1}$, JIASONG FANG ${ }^{1,2 *}$
}

${ }^{1}$ Shanghai Engineering Research Center of Hadal Science and Technology, College of Marine Sciences, Shanghai Ocean University, Shanghai 201306, PR China (zxie@shou.edu.cn, m180200470@st.shou.edu.cn, *correspondence: jsfang@shou.edu.cn)

${ }^{2}$ Department of Natural Sciences, Hawaii Pacific University, Honolulu, HI 96813, USA

A piezotolerant, $\mathrm{H}_{2} \mathrm{O}_{2}$-tolerant, slightly halophilic bacterium (strain $\mathrm{NBT} \mathrm{E} \mathrm{E}^{\mathrm{T}}$ ) was isolated from a deep-sea sediment sample collected from the New Britain Trench at depth of $8900 \mathrm{~m}$. The strain was aerobic, motile, Gram-stainnegative, rod-shaped, oxidase-positive and catalase positive. Although 16S rRNA gene sequence analysis showed that strain NBT06E8 $8^{\mathrm{T}}$ is closely related to Halomonas aquamarina DSM $30161^{\mathrm{T}}(99.5 \%)$, Halomonas meridiana DSM $5425^{\mathrm{T}}(99.43 \%)$, and Halomonas axialensis $\mathrm{Althf}^{\mathrm{T}}$ (99.35\%), combined phylogenomic and phenotypic analysis revealed that strain NBT06E $8^{\mathrm{T}}$ represents a novel species of the genus Halomonas. Growth of the strain was observed at $4-45^{\circ} \mathrm{C}$ (optimum $30^{\circ} \mathrm{C}$ ), at $\mathrm{pH} 5-11$ (optimum 8-9) and in $0.5-21 \%(\mathrm{w} / \mathrm{v}) \mathrm{NaCl}$ (optimum 3-7\%). The optimum pressure for growth was 0.1$30 \mathrm{MPa}$ (megapascal) with tolerance up to $60 \mathrm{MPa}$. Under optimum growth conditions, the strain could tolerant $15 \mathrm{mM}$ $\mathrm{H}_{2} \mathrm{O}_{2}$. Whole-genome sequencing analysis of this strain revealed that it contains 39 genes affiliated with anti-oxidative stress, including $\operatorname{oxy} R$ (transcriptional regulator), kat (catalase), sod (superoxide peroxidase), ahpCF (alkyl hydroperoxide reductase), $o h r$ (organic hydroperoxide resistance protein), $c c p$ (cytochrome $c$ peroxidase), prx (peroxiredoxin), trx (thioredoxin), grx (glutaredoxin) tpx (thiol peroxidase), gor (glutathione reductase) and so on. In addition, strain NBT06E $8^{\mathrm{T}}$ also owns 11 DNA repair proteins which may promptly repair DNA damages caused by oxidative stress. These genes are important contributors to oxidative stress resistance by maintaining the intracellular redox balance and macromolecules stability. This study indicated that strain NBT06E $8^{\mathrm{T}}$ possesses multidirectional mechanisms of oxidative stress sensing, regulation, and defense. New findings on oxidative stress mechanisms of this strain will broaden our knowledge of stress adaptation mechanisms of deep-sea bacteria and potentiate the biotechnological application of Halomonas species in the future. 